\title{
Simulation of mono-ply and multi-ply woven composite reinforcements forming
}

\author{
Nahiene Hamila* — Fabrice Hélénon* — Philippe Boisse* \\ Sylvain Chatel** \\ * Laboratoire de Mécanique des Contacts et des Solides, INSA de Lyon \\ Bâtiment Jacquard, Rue Jean Capelle, F-69621 Villeurbanne cedex \\ ** EADSIW, DCR/SP/SM, 12 rue Pasteur, F-92152 Suresnes \\ \{Nahiene.Hamila, Fabrice.Helenon, Philippe.Boisse\}@insa-lyon.fr \\ Sylvain.Chatel@eads.net
}

ABSTRACT. The numerical simulation of composite forming permits to envisage the feasibility of a process without defect but also to know the directions of the reinforcements after shaping. These directions condition strongly the mechanical behaviour of the final textile composite structure. In addition, the angles between warp and weft yarns influence the permeability of the reinforcement and thus the filling of the resin in the case of a liquid moulding process. The forming of composite reinforcement can be made on a single ply or simultaneously on several plies. In this paper the different approaches for the textile reinforcement forming simulation are described. A three node element with arbitrary directions of the yarns with regard to the element sides is presented and used for the simultaneous hemispherical forming of three layers.

RÉSUMÉ. La simulation numérique de la mise en forme des composites permet d'analyser la faisabilité d'un procédé et ses défauts, mais aussi de déterminer les directions des renforts après la mise en forme. Ces directions conditionnent fortement le comportement mécanique de la pièce composite en service. La mise en forme peut concerner un seul pli ou bien plusieurs plis pouvant être mis en forme simultanément. Dans ce travail, les différentes approches actuellement utilisées pour la simulation de la mise en forme des renforts tissés sont décrites. En particulier un élément triangulaire à trois nœuds dont les directions des mèches sont quelconques vis-à-vis des côtés de l'élément est présenté et utilisé pour le formage hémisphérique simultané de trois plis.

KEYWORDS: fabrics/textiles, composites, forming, finite element, meso-macro.

MOTS-CLÉS : renforts tissés, composites, mise en forme, éléments finis, meso-macro.

DOI:10.3166/REMN.17.919-931 @ 2008 Lavoisier, Paris

REMN - 17/2008. Giens 2007, pages 919 to 931 


\section{Introduction}

A significant effort currently relates to the modeling and the simulation of large strains of composite woven reinforcement. The forming process of woven reinforcements is essential for the manufacturing of textile composites. For example, the first stage of the RTM process (Resin Transfer Moulding) consists of making a dry textile preform before resin injection. In the draping of preimpregnated or in the forming of CFRTP (Carbon Fibre Reinforced Thermo-Plastic), the matrix is present but is not hardened and the composite deformation is led by that of the reinforcement. The composite forming process exploits the relative movement of fibres made possible by the absence of the cohesion of the matrix. The woven textile reinforcements are particularly effective in the case of non developable geometries because of the interlacing of the warp and the weft. It is difficult (often impossible) to obtain this type of geometry with unidirectional reinforcements. A simulation tool makes it possible not only to determine the feasibility of a process, to detect the possible defects, but also to know the directions of the reinforcements after processing, which is essential for calculations.

The alternative to the geometrical methods (the fishnet algorithm) for woven reinforcement forming [1,2] consists of a mechanical analysis of the fabric deformation subjected to the boundary conditions prescribed by the forming process. This requires a model of the woven reinforcement, its mechanical behavior and a numerical method, which is generally the finite element method. The mechanical behavior of fabrics is complex due to the interactions of the yarns related to the weave. It is a multi-scale problem. The macroscopic behavior is closely related to the interactions of the yarns on a mesoscopic scale (scale of the woven unit cell) and on a microscopic scale (scale of fibres constituting the yarns). Although there has been much work done in the field, there is no globally accepted model to describe the principal aspects of the mechanical behavior of fabrics.

\section{Continuous approach}

A first family of models is obtained by homogenizing the mechanical behavior of the meso-structure and by assuming the fabric is an anisotropic continuum [3-5]. For analyses of large strains, the finite element codes frequently use the elastic rate constitutive equations (hypoelastic laws):

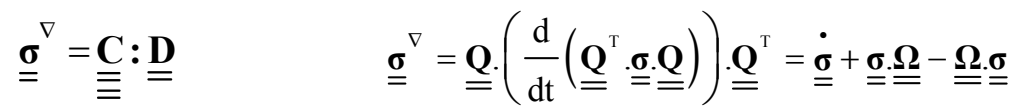

$\underline{\underline{\boldsymbol{\sigma}}}$ and $\underline{\underline{\mathbf{D}}}$ are respectively the Cauchy stress tensor and the strain rate tensor. $\underline{\boldsymbol{\sigma}}^{\nabla}$ is the objective derivative of $\underset{\boldsymbol{\sigma}}{=}$ associated with the rotation $\underline{\underline{\mathbf{Q}}}$.The classical incremental 
scheme of Hughes and Winget [6] for stress update is built starting from Equation [1]:

$$
\begin{aligned}
{\left[\boldsymbol{\sigma}^{\mathrm{n}+1}\right]_{\mathrm{e}_{i}^{n+1}} } & =\left[\boldsymbol{\sigma}^{\mathrm{n}}\right]_{\mathrm{e}_{1}^{\mathrm{n}}}+\left[\mathbf{C}^{\mathrm{n}+1 / 2}\right]_{\mathrm{e}_{i}^{\mathrm{n}+1 / 2}}[\Delta \boldsymbol{\varepsilon}]_{\mathrm{e}_{i}^{n+1 / 2}} \\
\text { with } \quad[\Delta \boldsymbol{\varepsilon}]_{\mathrm{e}_{i}^{n+1 / 2}} & =\left[\mathbf{D}^{\mathrm{n}+1 / 2}\right]_{\mathrm{e}_{1}^{\mathrm{nit} / 2}} \Delta \mathrm{t}
\end{aligned}
$$

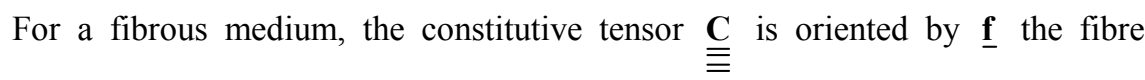
direction. $\underline{\mathbf{f}}$ is a material direction. Let $\left\{\underline{\mathbf{e}}_{\mathrm{i}}\right\}$ denotes the orthonormal reference basis obtained from the initial reference basis rotated by $\underline{\underline{\mathbf{Q}}}$. $\underline{\mathbf{f}}$ is in general not fixed in $\left\{\underline{\mathbf{e}}_{\mathrm{i}}\right\}$ since it is a material direction. The initial fibre direction $\underline{\mathbf{f}}^{0}$ is transformed by $\underline{\underline{F}}$ (the gradient tensor) into $\underline{\mathbf{f}}=\underline{\mathbf{f}}_{1}$, while $\left\{\underline{\mathbf{e}}_{\mathrm{i}}\right\}$ is rotated by $\underline{\underline{\mathbf{Q}}}$. To treat this situation, characteristic of the fibrous media, two approaches were developed within the framework of the hypoelastic formulations presented above. The first one $[4,5]$ uses the classical objective derivative of Green Naghdi which is used in some finite element codes such as ABAQUS. All of the calculations are performed in the reference basis rotated by the rotation of the polar decomposition. The constitutive operator is obtained in this reference frame from its specific form in the reference frame of the fibers by a basis change. The second approach [7][8] consists of using another objective derivative defined from the rotation of the fibre. It can be shown that in certain cases, the second approach is preferred.

\section{Discrete approach}

On the other hand, certain approaches describe woven fabrics by entirely discrete models. Each fibre or yarn is modelled by a straight or curved beam (or other type of finite element) and the contacts are managed or replaced by springs [9][10][11][12]. Taking into account the simplicity of each component, the complete woven structural deformation can be calculated. Nevertheless, the numerical effort required by this approach is very consuming and limits the complexity of the possible local modelling.

\section{The semi-discrete approach}

This approach is detailed in this paper. Particularly a new three node triangle composed of woven meshes of unspecified direction with respect to the edges of the element is presented. 


\subsection{Loads on a woven unit cell. Interior virtual work}

In the present approach the textile composite reinforcements under consideration are composed of a discrete number of woven unit cells such as shown on Figure 1. The unit woven cell on Figure 1 is a plain weave cell for simplicity but this unit woven shell can be any type (twill, satin...). The diameter of the fibres constituting the textile (usually carbon, glass or aramid) is very small (5 to $7 \mu \mathrm{m}$ for carbon, $10-$ $20 \mu \mathrm{m}$ for aramid, 5-25 $\mu \mathrm{m}$ for glass) [13]. This diameter is extremely small in comparison to their length in case of continuous fibres. Consequently the main loading that can be applied to these fibres is a tensile load in the fibre direction. The yarns are made of thousands of fibres. These fibres can slide relatively and the tensile stiffness is still much larger than the other rigidities. (The textile reinforcement under consideration is dry i.e. with no matrix).

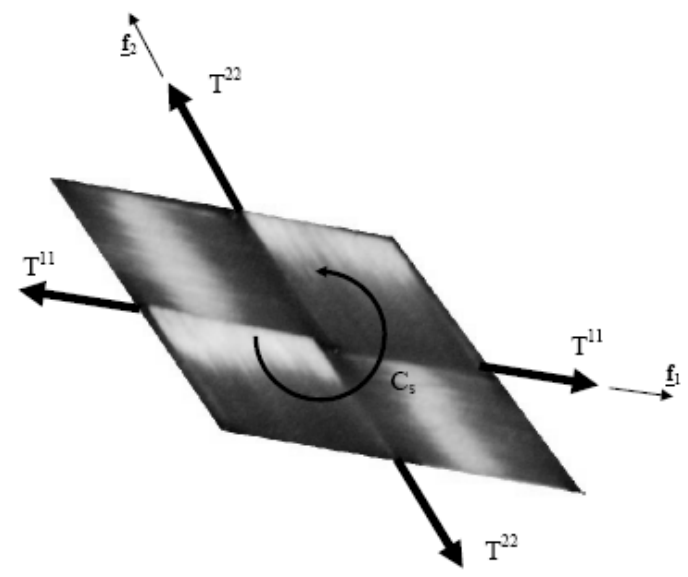

Figure 1. Unit woven cell submitted to tension and in plane shear

The loads on this unit cell are assumed to result in two tensions $\mathrm{T}^{11}$ and $\mathrm{T}^{22}$ in the warp and weft directions $\underline{f}_{1}$ and $\underline{f}_{2}$ and a torque $C_{s} \underline{f}_{3}$ which is due to the internal actions from warp yarn on weft yarns in reaction to in plane shear $\left(\mathrm{f}_{3}\right.$ is perpendicular to $\underline{f}_{1}$ and $\underline{f}_{2}$ ). Because the yarns are composed of many fibres with a very small diameter, the shear stiffness is small and the torque $\mathrm{C}_{\mathrm{s}}$ too. Nevertheless, it will be seen that it is important to consider this in-plane shear behaviour because it plays a significant role in some cases and especially in wrinkle development which is an important aspect in draping simulations.

From these definitions of the loads on a unit woven cell, the interior virtual work in a textile reinforcement in a virtual displacement field $\underline{\eta}$, can be written: 


$$
\mathrm{W}_{\text {int }}(\underline{\eta})=\sum_{\mathrm{p}=1}^{\text {ncell }}{ }^{\mathrm{p}} \varepsilon_{11}(\underline{\eta}){ }^{\mathrm{p}} \mathrm{T}^{11 \mathrm{p}} \mathrm{L}_{1}+{ }^{\mathrm{p}} \varepsilon_{22}(\underline{\eta}){ }^{\mathrm{p}} \mathrm{T}^{22 \mathrm{p}} \mathrm{L}_{2}+\sum_{\mathrm{p}=1}^{\text {ncell }}{ }^{\mathrm{p}} \gamma(\underline{\eta}){ }^{\mathrm{p}} \mathrm{C}_{\mathrm{s}}
$$

where ncell is the number of unit woven cell of the domain $\Omega$ under consideration, $\varepsilon_{11}(\underline{\eta})$ et $\varepsilon_{22}(\underline{\eta})$ are the linear axial strain in the warp and weft directions $\underline{f}_{1}$ and $\underline{f}_{2}$ in the virtual field $\underline{\eta} . \gamma(\underline{\eta})$ is the angle change between warp weft direction in the virtual field $\underline{\eta}$. $L_{1}$ and $L_{2}$ are the length of the unit cell in warp and weft direction. ${ }^{p} A$ means that the quantity $\mathrm{A}$ is considered for the cell number $\mathrm{p}$.

It has been shown by experiments that the tensions are reasonably independent of the shear angle [14]. As the tensile behaviour is biaxial it will be in the form $\mathrm{T}^{11}\left(\varepsilon_{11}, \varepsilon_{22}\right), \mathrm{T}^{22}\left(\varepsilon_{11}, \varepsilon_{22}\right)$. It will also be assumed that the shear couple does not depend on the axial strain and will be in the form $\mathrm{C}_{\mathrm{s}}(\gamma)$. This is probably less true [15-17] but there is not enough available data and models concerning the influence of tensions on shear stiffness for it to be taken it into account.

For a given composite reinforcement these material data can be identified either by experiments [14][18-21] or by mesoscopic analyses i.e. 3D F.E. simulations of the deformation of the woven unit cell [22][23].

\subsection{Three node semi-discrete finite element}

Although most forming processes are quasi-static, the simulations of material forming processes are often made within explicit dynamic approaches [24]. Within a finite element approximation, the dynamic equation in the set of degrees of freedom

$$
\mathbf{M} \ddot{\mathbf{u}}_{\mathrm{n}}+\mathbf{C} \dot{\mathbf{u}}_{\mathrm{n}}=\mathbf{F}_{\mathrm{ext}}-\mathbf{F}_{\mathrm{int}}
$$

is integrated in time using an explicit scheme. $\mathbf{M}$ and $\mathbf{C}$ are mass and damping matrices, $\mathbf{u}_{\mathrm{n}}$ is the single column matrix of the degrees of freedom (three displacement components per node in the global frame). $\mathbf{F}_{\text {ext }}$ and $\mathbf{F}_{\text {int }}$ are single column matrix of the components of the exterior and interior nodal loads. In the case of textile reinforcements, where the interior virtual work is in the form [4], the nodal interior loads are such as:

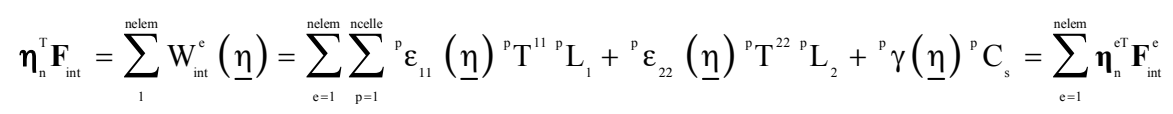

The superscript e denotes that the quantity is considered for the element e. The nodal interior loads $\mathbf{F}_{\text {int }}$ is the assembly of the elementary nodal interior loads $\mathbf{F}_{\text {int }}^{\mathrm{e}}$. In an explicit scheme, the computations at the element level only require the 
computations of these elementary nodal interior loads. For simplicity of the presentation the elementary virtual interior load is split in tensile and shear parts:

$$
\begin{aligned}
& \mathrm{W}_{\text {int }}^{\mathrm{e}}(\underline{\eta})=\mathrm{W}_{\text {int }}^{\mathrm{te}}(\underline{\eta})+\mathrm{W}_{\text {int }}^{\mathrm{se}} \underline{(\underline{\eta})} \\
& \mathrm{W}_{\text {int }}^{\mathrm{te}}(\underline{\eta})=\boldsymbol{\eta}_{\mathrm{n}}^{\mathrm{eT}} \mathbf{F}_{\text {int }}^{\mathrm{te}}=\sum_{\mathrm{p}=1}^{\text {ncelle }}{ }^{\mathrm{p}} \varepsilon_{11}(\underline{\eta}){ }^{\mathrm{p}} \mathrm{T}^{11 \mathrm{p}} \mathrm{L}_{1}+{ }^{\mathrm{p}} \varepsilon_{22}(\underline{\eta}){ }^{\mathrm{p}} \mathrm{T}^{22 \mathrm{p}} \mathrm{L}_{2} \\
& \mathrm{~W}_{\text {int }}^{\mathrm{se}}(\underline{\eta})=\boldsymbol{\eta}_{\mathrm{n}}^{\mathrm{eT}} \mathbf{F}_{\text {int }}^{\mathrm{se}}=\sum_{\mathrm{p}=1}^{\text {ncelle }}{ }^{\mathrm{p}} \gamma(\underline{\eta}){ }^{\mathrm{p}} \mathrm{C}_{\mathrm{s}}
\end{aligned}
$$

\subsubsection{Geometry of the three node finite element made of woven cells}

The three node triangle shown Figure 2 is composed of ncelle woven cells such as described in Section 4.2. As usual, the "natural" material coordinates (or coordinates in the reference element) $\xi^{1}, \xi^{2}$ are defined along the sides of the element. These coordinates have the following values at the nodes of the triangle : $\mathrm{M}_{1}(0,0), \mathrm{M}_{2}(1,0), \mathrm{M}_{3}(0,1)$. The displacement $\underline{\mathrm{u}}$ and the position $\underline{\mathrm{x}}$ of a point $\mathrm{P}$ within the element are interpolated from the values at node:

$$
\underline{u}(P)=\sum_{i=1}^{3} N_{i} \underline{u}\left(M_{i}\right) \quad \underline{x}(P)=\sum_{i=1}^{3} N_{i} \underline{x}\left(M_{i}\right)
$$

With $\quad \mathrm{N}_{1}=1-\xi^{1}-\xi^{2} \quad \mathrm{~N}_{2}=\xi^{1} \quad \mathrm{~N}_{3}=\xi^{3}$

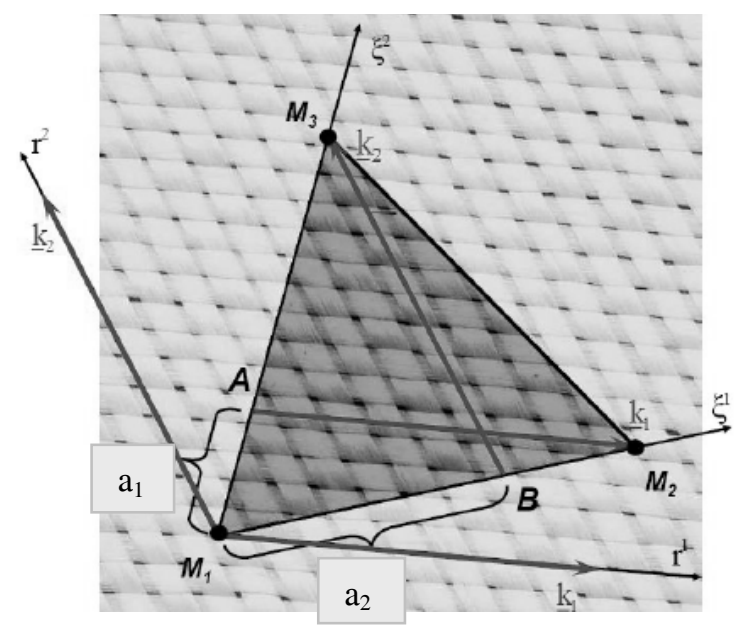

Figure 2. Three-node finite element made of unit woven cells 
The material coordinates $r^{1}, r^{2}$ are defined along the warp and weft directions (Figure 2). $r^{1}$ is equal to zero on $M_{1} M_{3}$ and is equal to 1 in $M_{2} . r^{2}$ is equal to zero on $\mathrm{M}_{1} \mathrm{M}_{2}$ and equal to 1 in $\mathrm{M}_{3}$.

Denoting $\mathrm{a}_{1}=\mathrm{M}_{1} \mathrm{~A}$ and $\mathrm{a}_{2}=\mathrm{M}_{1} \mathrm{~B}$ (Figure 2), the coordinates $\xi^{1}, \xi^{2}$ and $\mathrm{r}^{1}, \mathrm{r}^{2}$ are related

$$
\left|\begin{array}{l}
\xi^{1} \\
\xi^{2}
\end{array}=\left[\begin{array}{cc}
1 & -b \\
-a & 1
\end{array}\right]\right| \begin{aligned}
& r^{1} \\
& r^{2}
\end{aligned} \quad\left|\begin{array}{l}
r^{1} \\
r^{2}
\end{array}=\frac{1}{1-a b}\left[\begin{array}{cc}
1 & b \\
a & 1
\end{array}\right]\right| \begin{aligned}
& \xi^{1} \\
& \xi^{2}
\end{aligned}
$$

The material vectors $\underline{\mathrm{k}}_{1}, \underline{\mathrm{k}}_{2}$ are defined from $\mathrm{r}^{1}, \mathrm{r}^{2}$ :

$$
\underline{\mathrm{k}}_{1}=\frac{\partial \underline{\mathrm{x}}}{\partial \mathrm{r}^{1}} \quad \underline{\mathrm{k}}_{2}=\frac{\partial \underline{\mathrm{x}}}{\partial \mathrm{r}^{2}} \quad \text { and consequently } \quad \underline{\mathrm{k}}_{1}=\underline{\mathrm{AM}}_{2} \quad \underline{\mathrm{k}}_{2}=\underline{\mathrm{BM}}_{3}
$$

\subsubsection{Tensile elementary nodal interior load}

Denoting $\underline{\mathrm{k}}^{\alpha}(\alpha=1$ or 2$)$ the contravariant vectors associated to $\underline{\mathrm{k}}_{\alpha}$ i.e. such as

$$
\underline{\mathrm{k}}^{\alpha} \cdot \underline{\mathrm{k}}_{\beta}=\delta_{\beta}^{\alpha}
$$

The virtual displacement gradient can be expressed in the warp and weft frame:

$$
\underline{\underline{\nabla}}(\underline{\eta})=\frac{1}{2}\left(\frac{\partial \underline{\eta}}{\partial \mathrm{r}^{\alpha}} \cdot \underline{\mathrm{k}}_{\beta}+\frac{\partial \underline{\eta}}{\partial \mathrm{r}^{\beta}} \cdot \underline{\mathrm{k}}_{\alpha}\right) \underline{\mathbf{k}}^{\alpha} \otimes \underline{\mathrm{k}}^{\beta}
$$

Consequently

$$
\varepsilon_{\alpha \alpha}(\underline{\eta})=\left((\underline{\underline{\nabla}}(\underline{\eta})) \cdot \underline{\mathrm{f}}_{\alpha}\right) \cdot \underline{\mathrm{f}}_{\alpha}=\frac{\partial \underline{\eta}}{\partial \mathrm{r}^{\alpha}} \cdot \frac{\underline{\mathrm{k}}_{\alpha}}{\left\|\underline{\mathbf{k}}_{\alpha}\right\|^{2}}
$$

the elementary tensile virtual work can be written :

$$
\mathrm{W}_{\mathrm{int}}^{\mathrm{te}}(\underline{\eta})=\boldsymbol{\eta}_{\mathrm{n}}^{\mathrm{er}} \mathbf{F}_{\text {int }}^{\mathrm{te}}=\sum_{\mathrm{p}=1}^{\text {nelle }}{ }^{\mathrm{p}}\left(\frac{\partial \underline{\eta}}{\partial \mathrm{r}^{1}} \cdot \frac{\underline{\mathrm{k}}_{1}}{\left\|\underline{\mathrm{k}}_{1}\right\|^{2}}\right){ }^{\mathrm{p}} \mathrm{T}^{11}{ }^{11 \mathrm{p}} \mathrm{L}_{1}+\left(\frac{\partial \underline{\eta}}{\partial \mathrm{r}^{2}} \cdot \frac{\underline{\mathrm{k}}_{2}}{\left\|\underline{\mathrm{k}}_{2}\right\|^{2}}\right){ }^{\mathrm{p}} \mathrm{T}^{22 \mathrm{p}} \mathrm{L}_{2}
$$

Denoting $\eta_{i}$ the components number i ( $i=1$ to 3 ) of the virtual displacement $\underline{\eta}$ in the global frame and $\eta_{i 1}, \eta_{i 2}, \eta_{i 3}$ the values of these components at nodes $M_{1}, M_{2}$, $\mathrm{M}_{3}$, accounting for the interpolation [10], 


$$
\frac{\partial \eta_{i}}{\partial r^{\alpha}}=\frac{\partial \eta_{i}}{\partial \xi^{\beta}} \frac{\partial \xi^{\beta}}{\partial r^{\alpha}}=\left[\begin{array}{lll}
a_{\alpha}-1 & 1 & -a_{\alpha}
\end{array}\right]\left[\begin{array}{lll}
\eta_{i 1} & \eta_{i 2} & \eta_{i 3}
\end{array}\right]^{\mathrm{T}}
$$

Consequently

$$
\mathrm{W}_{\mathrm{int}}^{\mathrm{te}}(\underline{\eta})=\boldsymbol{\eta}_{\mathrm{n}}^{\mathrm{eT}} \mathbf{F}_{\text {int }}^{\text {te }}=\left(\sum_{\mathrm{p}=1}^{\text {neelle }}{ }^{\mathrm{p}} \mathrm{B}_{1 \mathrm{j}}{ }^{\mathrm{p}} \mathrm{T}^{11 \mathrm{p}} \mathrm{L}_{1} \frac{{ }^{\mathrm{p}} \mathrm{L}_{1}}{\left\|\underline{\mathrm{k}}_{1}\right\|^{2}}+{ }^{\mathrm{p}} \mathrm{B}_{2 \mathrm{ij}}{ }^{\mathrm{p}} \mathrm{T}^{22} \frac{{ }^{\mathrm{p}} \mathrm{L}_{2}}{\left\|\underline{\mathrm{k}}_{2}\right\|^{2}}\right) \eta_{\mathrm{ij}}
$$

with

$$
\begin{array}{lll}
\mathrm{B}_{1 \mathrm{ii}}=\left(\mathrm{a}_{1}-1\right) \mathrm{k}_{1 \mathrm{i}} & \mathrm{B}_{1 \mathrm{i} 2}=\mathrm{k}_{1 \mathrm{i}} & \mathrm{B}_{1 \mathrm{i3}}=-\mathrm{a}_{1} \mathrm{k}_{1 \mathrm{i}} \\
\mathrm{B}_{2 \mathrm{i} 1}=\left(\mathrm{a}_{2}-1\right) \mathrm{k}_{2 \mathrm{i}} & \mathrm{B}_{2 \mathrm{i} 2}=-\mathrm{a}_{2} \mathrm{k}_{2 \mathrm{i}} & \mathrm{B}_{2 \mathrm{i} 3}=\mathrm{k}_{2 \mathrm{i}}
\end{array}
$$

The elementary nodal tensile interior loads are determined. Because of the linear interpolation, the strain interpolation terms $\mathrm{B}_{\text {oij }}$ are very simple and constant in the element. The strains and the tensions are constant in the element, consequently:

$$
\left(\mathrm{F}_{\text {int }}^{\text {te }}\right)_{\mathrm{ij}}=\operatorname{ncelle}\left(\mathrm{B}_{1 \mathrm{ij}} \mathrm{T}^{11}\left(\varepsilon_{11}, \varepsilon_{22}\right) \frac{\mathrm{L}_{1}}{\left\|\underline{\mathrm{k}}_{1}\right\|^{2}}+\mathrm{B}_{2 \mathrm{ij}} \mathrm{T}^{22}\left(\varepsilon_{11}, \varepsilon_{22}\right) \frac{\mathrm{L}_{2}}{\left\|\underline{\mathrm{k}}_{2}\right\|^{2}}\right)
$$

REMARK - in Equation [22], ncelle can be non-integer accounting for unit woven cells crossing the boundary of the element

The angle variation between the warp and weft directions in the virtual field $\gamma(\underline{\eta})$ is given by the gradient of the virtual displacement:

with:

$$
\gamma(\underline{\eta})=\left(\underline{\nabla} \underline{\underline{\eta}} \cdot \underline{\mathrm{f}}_{1}\right) \cdot \underline{f}^{2}+\left(\underline{\underline{\nabla}} \cdot \underline{\underline{\mathrm{f}}} \underline{\underline{f}}_{2}\right) \cdot \underline{\mathrm{f}}^{1}
$$

$$
\underline{\mathrm{f}}_{1}=\frac{\underline{\mathrm{k}}_{1}}{\left\|\underline{\mathrm{k}}_{1}\right\|}, \quad \underline{\mathrm{f}}_{2}=\frac{\underline{\mathrm{k}}_{2}}{\left\|\underline{\mathrm{k}}_{2}\right\|}, \quad \underline{\mathrm{f}}^{1}=\frac{\underline{\mathrm{k}}^{1}}{\left\|\underline{\mathrm{k}}^{1}\right\|}, \quad \underline{\mathrm{f}}^{2}=\frac{\underline{\mathrm{k}}^{2}}{\left\|\underline{\mathrm{k}}^{2}\right\|}
$$

The expression of the components of the virtual displacement gradient [15] and Equation [18] gives the interpolation of the virtual angle variation $\gamma(\underline{\eta})$

$$
\gamma(\underline{\eta})=\left(B_{1 \mathrm{ij}} \frac{\underline{\mathrm{k}}^{1}}{\left\|\underline{\mathrm{k}}_{1}\right\|} \cdot \frac{\underline{\mathrm{k}}^{2}}{\left\|\underline{\mathrm{k}}^{2}\right\|}+\mathrm{B}_{3 \mathrm{ij}} \frac{\left\|\underline{\mathrm{k}}^{2}\right\|}{\left\|\underline{\mathrm{k}}_{1}\right\|}+\mathrm{B}_{4 \mathrm{ij}} \frac{\left\|\underline{\mathrm{k}}^{1}\right\|}{\left\|\underline{\mathrm{k}}_{2}\right\|}+\mathrm{B}_{2 \mathrm{ij}} \frac{\underline{\mathrm{k}}^{2}}{\left\|\underline{\mathrm{k}}_{2}\right\|} \cdot \frac{\underline{\mathrm{k}}^{1}}{\|\underline{\mathrm{k}}\|}\right) \eta_{\mathrm{ij}}=\mathrm{B}_{\gamma \mathrm{ji}} \eta_{\mathrm{ij}}
$$


with:

$$
\begin{array}{lll}
\mathrm{B}_{3 \mathrm{i} 1}=\left(\mathrm{a}_{2}-1\right) \mathrm{k}_{1 \mathrm{i}} & \mathrm{B}_{3 \mathrm{i} 2}=-\mathrm{a}_{2} \mathrm{k}_{1 \mathrm{i}} & \mathrm{B}_{3 \mathrm{i} 3}=\mathrm{k}_{1 \mathrm{i}} \\
\mathrm{B}_{4 \mathrm{i} 1}=\left(\mathrm{a}_{1}-1\right) \mathrm{k}_{2 \mathrm{i}} & \mathrm{B}_{4 \mathrm{i} 2}=\mathrm{k}_{2 \mathrm{i}} & \mathrm{B}_{4 \mathrm{i} 3}=-\mathrm{a}_{1} \mathrm{k}_{2 \mathrm{i}}
\end{array}
$$

$\mathrm{B}_{1 \mathrm{ij}}, \mathrm{B}_{2 \mathrm{ij}}$ have been given in Equation [20] and [21].

$B_{\gamma i 1}$, given by Equation [25] is constant in the three node finite element, therefore:

$$
\left(\mathrm{F}_{\mathrm{int}}^{\mathrm{se}}\right)_{\mathrm{ij}}=\text { ncelle } \cdot \mathrm{B}_{\gamma \mathrm{ij}} \cdot \mathrm{C}_{\mathrm{s}}(\gamma)
$$

\section{Draping on a circular table}

The draping of an initially plane square textile sheet over a circular table is considered (The mesh is composed of $2 \times 100 \times 100$ triangles). The proposed approach based on the three node element give a satisfactory shape after draping that involves extensive wrinkling (Figure 3a). It can be seen that these wrinkling are well described by the membrane model. If some bending stiffness would be added, the wrinkling would be globally similar but they would be less numerous and larger as the bending stiffness increases. The draping is due to the weak shear stiffness and possible large warp weft angles variations.

If the in plane shear stiffness is neglected, the draped shape is shown Figure 9b. The draping is obtained but there is no wrinkle because the shear angle can be infinitely large as it is the case in the corners of the sheet.
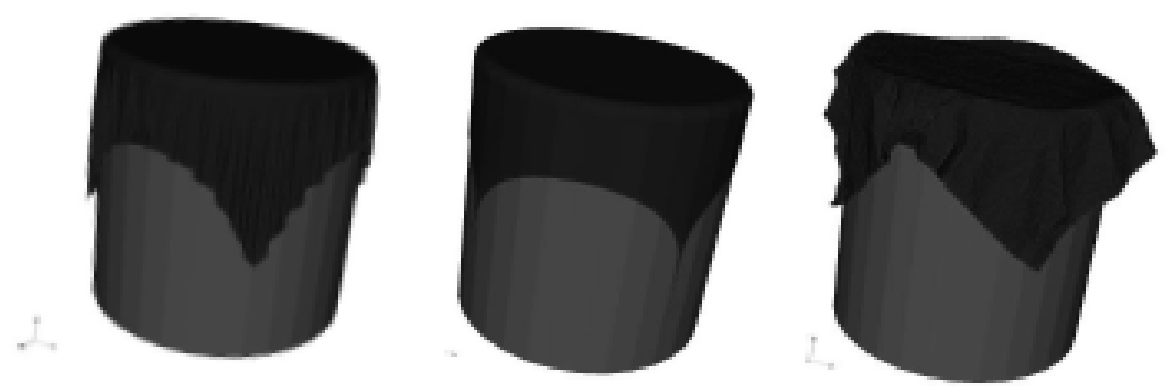

Figure 3. Fabric sheet draped over a circular table with stiffness (a) woven tensile and shear stiffness, (b) null shear stiffness and (c) isotropic shear stiffness

This solution is close to those that would be obtained by a kinematical model that appears to be unsuitable in this case. Finally Figure $9 \mathrm{c}$ shows the deformed shape obtained considering an isotropic behaviour of the sheet. The draping is not 
obtained. It could be for instance a paper sheet that is very difficult to drape on a circular table. That shows the very important role of the in plane shear stiffness in draping/forming of membrane. A textile can be shaped on a double curved surface because there are possible large rotations between warp and weft fibres and in plane shear is very weak. In the case of an isotropic membrane that is not possible.

\section{Three-ply forming simulation}

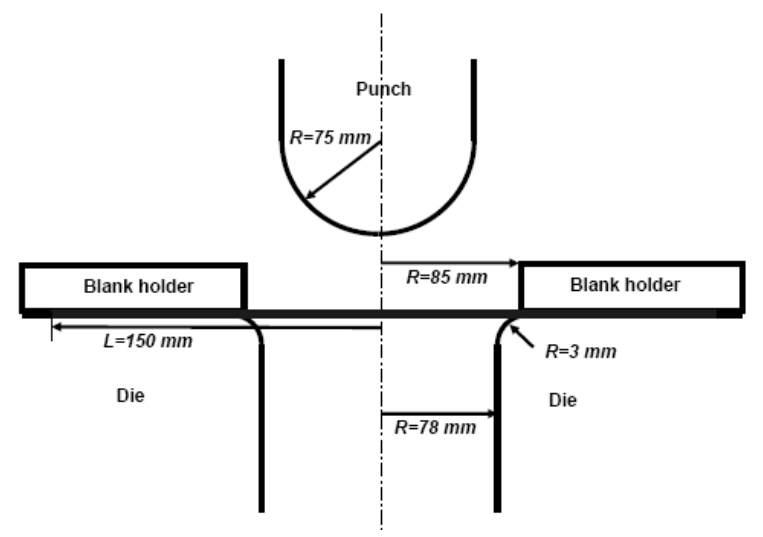

Figure 4. Geometry of the tools in a hemispherical deep drawing of a textile
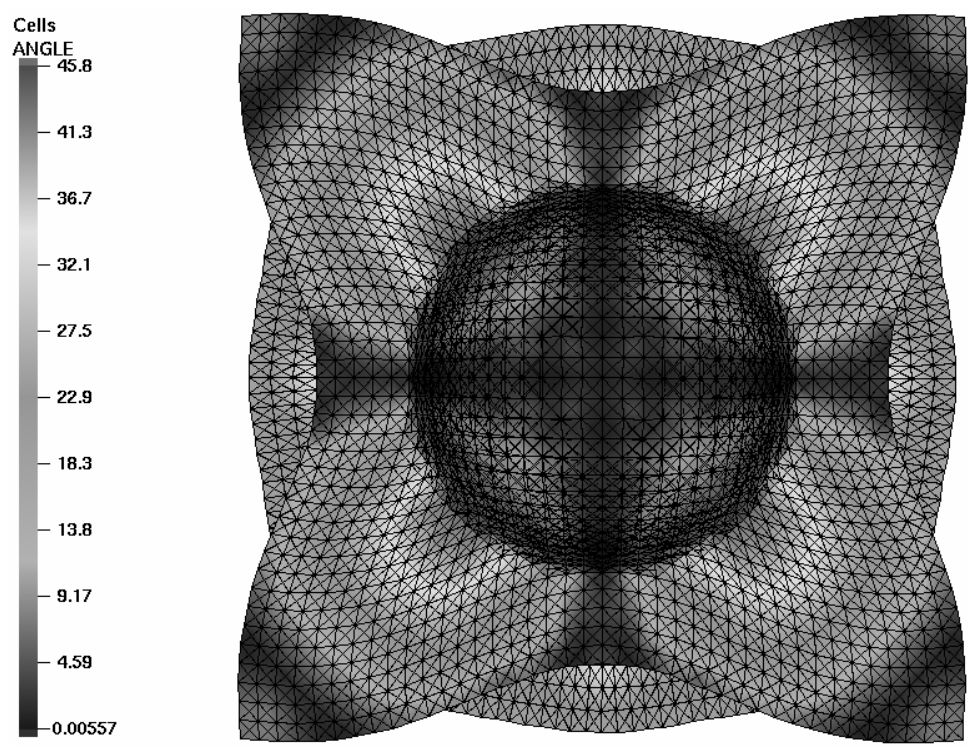

Figure 5. Deformed shape and distortion of the weft and warp for the central ply 
Figure 5 shows the result of the simulation of the simultaneous forming of three plies respectively at $\pm 45^{\circ}, 0-90^{\circ}, \pm 45^{\circ}$. The geometries of the hemispherical punch, die and blank holder are shown on Figure 4. The mesh of each ply is regular and is made of $20 \times 20 \times 4$ triangles. It is the same mesh for each ply. The difference comes from the orientation of vector $\underline{k}_{1}, \underline{\mathrm{k}}_{2}$ (following the yarn orientations). This is a strong advantage of the three node element proposed in that paper in comparison to the elements where the yarns have to be directed by the sides of the elements [22][25].The variations of warp-weft angles obtained give a maximum value of $46^{\circ}$ (Figure 5). This is close to the locking angle in the shearing of the reinforcement and the start of the appearance of wrinkles in the strongly sheared zone. We can note in this example that the differences in orientations between the plies lead to great slippage between the layers. The deformed state of the stack depends on this friction between the plies which is an important point for multiply forming [26].

\section{Conclusions}

Composite reinforcement forming simulations is a field which undergoes many developments. Different approaches exist and mainly differ according to the scale at which the modelling is made. The semi-discrete three node finite element proposed in this paper is made of woven unit cells in biaxial tensions and in plane shear. This element is efficient because it is simple and close of the mechanical behaviour of woven materials. The membrane assumptions (no bending stiffness) used in the present approach lead to wrinkles when the shear angles are very large (for instance in the corners of the cube on which a fabric is draped in example 4.2). Nevertheless the shape and the number of those wrinkles depend on the bending stiffness of the fabric. The next step in the improvement of the element will be to take into account the bending rigidity.

\section{Acknowledgments}

The authors acknowledge the support of EADS Company and of the ITOOL European project.

\section{References}

Badel P., Vidal-Sallé E., Boisse P., "Computational determination of in plane shear mechanical behaviour of textile composite reinforcements, Computational Material Science", vol. 40, 2007, p. 439-448.

Belytschko T., "An overview of semidiscretisation and time integration procedures", Belytschko T. and Hughes T.J.R., (eds), Computation methods for transient analysis, Elsevier Science, 1983, p. 1-65. 
Ben Boubaker B., Haussy B. and Ganghoffer J.F., "Discrete models of fabrics accountting for yarn interactions", Europ. J. of Comput. Mech., vol. 14, n 6-7, 2005, p. 653-676.

Boisse P., Buet K., Gasser A., Launay J., "Meso-macro mechanical behaviour of textile reinforcements of thin composites", Composites Sci. and Tech., vol. 61, 2001, p. 395-401.

Boisse P., Gasser A., Hagege B., Billoet J.L., "Analysis of the mechanical behaviour of woven fibrous material using virtual tests at the unit cell level", International Journal of Materials Science, vol. 40, n 22, 2005, p. 5955-5962.

Boisse P., Zouari B., Daniel J. L., Importance of In-Plane Shear Rigidity in Finite Element Analyses of Woven Fabric Composite Preforming, Composites A., 2006, vol. 37, n 12 , p. 2201-2212.

Borouchaki H., Cherouat A., «Une nouvelle approche géométrique pour le drapage de structures composites ", Revue des Composites et Matériaux avancés, 2002, vol. 12, n 3.

Buet-Gautier K., Boisse P., Experimental analysis and modeling of biaxial mechanical behavior of woven composite reinforcements. Experim Mech., 2001, vol. 41, n 3, p. 260-269.

Cao J., Cheng H. S., Yu,T. X., Zhu B., Tao X. M., Lomov S. V., Stoilova Tz, Verpoest I., Boisse P., Launay J., Hivet G., Liu L., Chen J., De Graaf E. F., Akkerman R., "A cooperative benchmark effort on testing of woven composites", Proceedings of the $7^{\text {th }}$ Int. ESAFORM conference on Material Forming, Trondheim, Norway, 2004, p. 305-308.

Dong L., Lekakou C. and Bader M. G., "Processing of Composites, Simulations of the Draping of Fabrics with Updated Material Behaviour Law", Journal of Composite Materials, 2001, vol. 35, $\mathrm{n}^{\circ} 02$.

Duhovic M. and Bhattacharyya D., "Simulating the Deformation Mechanisms of knitted Fabric Composites", Composites A., 2006, vol. 37, n 11, p. 1897-1915.

DurvilleD., "Numerical simulation of entangled material properties", Journal of Material Science, 2005, vol. 40, p. 5941-5948.

Lebrun G., Bureau M. N., Denault J., "Evaluation of bias-extension and picture-frame test methods for the measurement of intraply shear properties of PP/glass commingled fabrics", Composite Structures, 2003, vol. 61, p. 341-352.

Gorczyca J., Sherwood J., Chen J., A friction model for thermostamping commingled glasspolypropylene woven fabrics, Composites Part A, 2007, vol. 38, p.393-406.

Hagege B., Boisse P., Billoet J.-L., "Finite element analyses of knitted composite reinforcement at large strain", Revue européenne des elements finis, vol. 14, n 6-7, 2005, p. $767-776$.

Hughes T.J.R., Winget J., "Finite rotation effects in numerical integration of rate constitutive equations arising in large-deformation analyses", International Journal of Numerical Methods in Engineering, 1980, vol. 15, p. 1862-1867.

Launay J., Hivet G., Duong A. V., Boisse P., "Experimental analysis of the influence of tensions on in plane shear", Composites Science and Technology, 2007. 
Lomov S.V., Verpoest I., "Model of shear of woven fabric and parametric description of shear resistance of glass woven reinforcements", Composites Sc. and Tech., 2006, 66, p. 919-933.

Peng X., Cao J., A continuum mechanics-based non-orthogonal constitutive model for woven composite fabrics, Composites: Part A, 2005, vol. 36, p. 859-874.

Pickett A. K., Creech G. and de Luca P., "Simplified and Advanced Simulation Methods for Prediction of Fabric Draping”, European Journal of Comp. Mech., 2005, vol. 14, n 6-7, p. 677-691.

Potter K., Bias extension measurements on cross-plied unidirectional prepreg. Composites Part A, 2002, vol. 33, p. 63-73.

Scardino F., An introduction to textile structures and their behaviour, Chou T.W., Ko F.K (eds.), Textile structural composites, Composite Material Series, Elsevier, 1989, p. 1-26.

Spencer A.J.M., Theory of fabric-reinforced viscous fluid. Composites Part A, 2000, vol. 31, p. $1311-1321$

Van Der Ween F., “Algorithms for draping fabrics on doubly curved surfaces”, International Journal of Numerical Method in Engineering, 1991, 31, p. 1414-1426.

Wang J, Page J.R, Paton R., "Experimental investigation of the draping properties of reinforcement fabrics", Composites Science and Technology, 1998, vol. 58, p. 229-237.

Willems A., Lomov S.V., Verpoest I., Vandepitte D., "Picture frame shear tests on woven textile composite reinforcements with controlled pretension", Cueto E., Chinesta P. (eds.) Conference ESAFORM 10, Zaragoza AIP Conf. Proc., 2007, vol. 907, p. 999-1004. 
